\title{
Watching the Crew: Commercial Aircraft Operations and the Surveillance of Pilots before and after MH370
}

\author{
Joel C. HoldawAY* \\ University of Victoria \\ holdaway@uvic.ca
}

\begin{abstract}
The disappearance of flight MH370 drew attention to some of the deficiencies of current surveillance technologies used to track aircraft. This article links these deficiencies to systemic controversies surrounding several aspects of aircraft surveillance that also includes the monitoring of pilots' drug and alcohol use and the gathering of flight data from the cockpit. I argue that the debate around aircraft surveillance began over a decade earlier, after the 9/11 terrorist attacks. Prior to 9/11, regulators, management, and pilots worked together in a model where thorough investigations would take place after every incident. Measured changes in policy that were satisfactory to all three parties would subsequently be recommended and implemented. I conclude that pilot discontent over regulatory decisions has translated into a host of undesirable outcomes, including less trust in the procedures and lower morale. Only through transparent negotiation can the trust between pilots, management, and regulators be restored.
\end{abstract}

Keywords: MH370; surveillance; aircraft; alcohol/drug testing; safety

\section{INTRODUCTION}

Because the U.S. Navy's pinger locator can pick up signals to a depth of 6,100 meters $(20,000$ feet), it should be

\footnotetext{
"I would like to express my gratitude to Dan Lett for his thoughtful editorial suggestions as well as Dr Colin Bennett for his recommendations during the writing process.
} 
able to hear the plane's data recorders even if they are in the deepest part of the search zone - about 5,800 meters $(19,000$ feet). But that's only if the locator gets within range of the black boxes - a tough task, given the size of the search area and the fact that the pinger locator must be dragged slowly through the water at just 1 to 5 knots (1 to $6 \mathrm{mph}$ ).

(Perry \& Ng, 2014, para 2)

ก

HE QUOTE ABOVE describes the most advanced technology available to the multinational operation that, at the time of writing, is attempting to locate Malaysian Airlines Flight 370 (MH370). One might expect that it would be relatively simple to trace one of the largest and most sophisticated aircraft in the world, yet a boat equipped with a pinger locator would have to travel at jogging speed and be within 300 metres of a crash sight to locate such a plane. In fact, modern-day pingers are based on technology developed in the 1950s (International Society of Air Investigators, 2014).

So why is it then, that we still use in-flight navigation and rescue technology from shortly after the Second World War? Though the answer may be unsatisfactory to many (especially those who lost a loved one aboard MH370), it lies in the well-established methods for gathering information and improving safety within commercial air operations. In this paper, I will reveal these methods, and conduct a limited discussion of the ways surveillance has been used since the establishment of commercial air travel. This paper will answer the following questions: in which ways has the increased security of air travel affected the surveillance of pilots, both inside and outside the workplace, and are these new forms of surveillance consistent with current academic concepts of privacy of the person? I subsequently predict that the industry will implement new modes of surveillance after MH370 - modes of surveillance that will ultimately be rejected by pilots and their unions, continuing a trend of lower morale and distrust between regulators and pilots that began with regulatory responses after the 2001 terrorist attacks. 
I begin by reviewing surveillance practices within contemporary commercial air travel. First, I discuss cockpit data collection procedures. Second, I focus on regulations and procedures for commercial pilots, specifically alcohol and drug testing. After this brief review, I analyze the significance of these uses of surveillance technology. The final section of this paper will link surveillance to broader issues in contemporary society, including conflicting theories of the right to privacy, the labour implications of increased surveillance on pilots, and the convergence of ideas concerning surveillance, justice, and safety.

Because few secondary sources on pilot surveillance and industry practices exist, the data in this study come from several personal interviews I conducted with industry and union stakeholders. In my semi-structured interviews, I asked interviewees basic questions concerning corporate surveillance practices, particularly those related to alcohol and drug testing, and union and pilot expectations. I also asked interviewees to give their predictions as to how surveillance would change after the disappearance of $\mathrm{MH} 370$. Interviews were conducted either via a 30-minute telephone conversation or through email correspondence. ${ }^{\text {1] }}$

\section{OVERVIEW OF CURRENT SURVEILLANCE PRACTICES}

\section{Flight data}

As demonstrated by the case of MH370, we know that at least some airplanes are not equipped with any sort of reliable wireless streaming of flight and voice data in the event of an emergency. However, a discussion with two airline representatives indicates that this is not always the case. When asked about current flight data monitoring systems in place by Air Canada, Blake Murphy, leader of the Vancouver Local Executive Council of the Air Canada Pilots Association (ACPA), specifically referenced MH370 to assure me that Air

\footnotetext{
${ }^{1}$ Two of my interviewees' concerns about privacy prevent me from publishing a transcript of our communication.
} 
Canada's Boeing 777 aircraft (the same type that went missing) are all equipped with Automatic Dependent Surveillance (ADS), a modern technology that Murphy claimed was not installed on MH370. A private surveillance company called FlightRadar24, however, claimed to have status reports from MH370 that originated from ADS signals (FlightRadar24, 2014). Thus, there appears to be an inconsistency between the information circulating in public and the information disclosed in my one-on-one interview. Further investigation revealed that ADS is not a single technology, but comprises three separately defined technologies. Airplanes equipped with ADS-B (and manually turn on the outgoing and incoming functions) send automated static updates of their GPS location and identifiers to other aircraft and Air Traffic Control. ADS-C, however, is a separate function that, if manually turned on, automatically sends out the GPS location, the aircraft identifier, and any flight data information requested from an Air Traffic controller to an “Air Traffic Service Unit" (ATSU). information that a controller could request (and thus receive without first asking the pilot) could include fuel levels, altitude, air speed, and navigational settings (personal communication, Blake Murphy, March 22, 2014; Anonymous Canadian Airline Pilot, March 15, 2014; Smith \& Evers, 2003). It is possible that Murphy was referring to ADS$\mathrm{C}$ when he claimed that MH370 was not equipped with this technology.

But why does this inconsistency matter to overall aircraft surveillance practices? I argue that it is a good example of the current complexity within aircraft systems. ADS is supposed to be a new technology designed to be used in correlation with Computer Pilot Data Link Communications (CPDLC), Traffic Control Avoidance System (TCAS), VHF Radio, and HF Radio. While some of these communications (such as ADS) remain voluntary in most regional jurisdictions (countries have national supremacy over their airspace), the older technologies (VHF Radio and HF Radio) are mandatory. This leads to a plethora of different technologies being used at the same time.

\footnotetext{
${ }^{2}$ I was surprised to learn that the pilot could turn many of these technologies off, including the black boxes.
} 
Experts claim that these new technologies increase safety (the question is how much) and since they are installed on Air Canada aircraft, we know that they are available (Rakas, Hansen, Jirajaruporn, $\&$ Bolic, 2003). The fact that these technologies were not installed globally on all aircraft, however, show that they do not come standard from Boeing's factory in Washington State. This raises a number of questions. First, Canadians may be curious whether the installation of these technologies are voluntary, or if they are regulated by federal government regulations (in Canada, air space is federal jurisdiction). If the Canadian government regulates them, are all aircraft flying in Canada monitored? I searched specifically for these questions and if you happen to be what pilots refer to as "a nervous flyer," my findings will likely not provide any comfort. The installation of these new GPS-based technologies in Canada remains completely voluntary. While jurisdictions are beginning to require mandatory use of the new technology (ADS and CPDLC rather than VHF and HF radio), each jurisdiction has set a different time frame for the conversion. While Australia has fully implemented these technologies (but not yet made them mandatory), the European Union will do so by 2017 and the United States by 2020 (European Union, 2011). Thus, one can hope that the old voice-based technologies and unreliable radar coverage will no longer be in use by 2020 .

At this point, one familiar with air travel may be curious - what about the International Civil Aviation Organization (ICAO) and International Air Transport Association (IATA)? What are their roles in the regulation of these technologies and why are they not able to ensure a more timely transition to twenty-first century technology? Even though nearly every country in the world has signed the Chicago Convention - the premiere treaty for air travel that is the backbone of the ICAO - the implementation of the convention is left to sovereign nations, who are expected to implement laws that are consistent with the treaty (International Civil Aviation Organization, 2010). Naturally, this leaves lots of room for inconsistencies. Furthermore, changes to the Chicago Convention require agreement from all states since there is no amending formula. Thus, contrary to 
what many people may think, despite nearly universal recognition of the IATA and the ICAO - the United Nations body responsible for air travel - there are no universal laws governing air space.

Due to the state-based nature of air travel regulation, responses to new technologies and procedures also tend to be state-based. This can be seen through pilot and flight attendant labour movements. Even if pilots across international boundaries are concerned about a specific procedure, their union will direct their lobbying efforts in a way that increases pressure on relevant national governments. WestJet's flight data management system (FDMS) provides a good example of how pilot resistance manifests. FDMS is a new technology that was installed on most of WestJet's Boeing 737 aircraft to monitor pilot responses within the cockpit, even in non-emergency situations. While the flight data recorders are designed to record the last thirty minutes of data inputs within the cockpit prior to an accident, FDMS gathers this information on a continual basis (essentially an advanced keystroke monitoring system within the cockpit). WestJet argued that they installed FDMS to monitor current practices to determine whether current pilot procedures and decisions are effective in ensuring the safe operation of the aircraft (Transport Canada, 2004). Not surprisingly, however, pilot concerns over privacy and surveillance were subsequently raised (and later rectified with national assurances). These concerns were raised within the context of Canadian regulations and practice, not with international organizations such as the ICAO or IATA ${ }^{\text {B }}$

\section{Alcohol and drug testing}

I suspect that many will agree that the currently diverse range of surveillance systems operating within the cockpit is not reassuring to the average Canadian traveller. Unfortunately, current alcohol and drug surveillance practices of pilots are equally complex. Like the data-gathering and communications-sharing methods outlined

\footnotetext{
${ }^{3}$ I came to this conclusion through the synthesis of various texts within my bibliography, primarily my three interviews, and the CAESN Annual report.
} 
above, each jurisdiction has the right to set their own laws and regulations concerning alcohol and drug testing. Since IACO and IATA do not play a role in these procedures, I will outline the different rules by comparing and contrasting two different countries, Canada and the United Kingdom.

Contrary to what many may believe, the Government of Canada has not enacted statutory legislation requiring alcohol and drug testing of pilots. This, however, does not mean that alcohol and drug testing does not occur. Within Canada, pilots (of all nationalities and airlines) may be tested for alcohol or drugs if there is reason to believe that they are in violation of a statutory law or company rule (personal communication, Anonymous Canadian Airline Management Member, March 22, 2014). drugs, pilots are in violation of statutory law if their blood alcohol content is higher than 0.2 percent. Additionally, my anonymous management interviewee informed me that his airline also conducts alcohol and drug tests during the hiring process. Unless there is reason for concern, alcohol and drug tests are not carried out during a pilot's semi-annual mandatory check-up with the airline's doctor.

The UK has similar alcohol and drug testing policies to Canada. According to the Railway and Transportation Safety Act 2003, "a constable may perform a preliminary test when she 'reasonably suspects that the person is committing an offence." While there is at least some consistency between the two countries, the fact that government regulations tend to be rather weak mean that there is still considerable variability in the actual drug and alcohol surveillance practices of airlines. Consider, for instance, the implementation of corporate substance abuse programs. While Canadian airlines appear to test prospective pilots during the hiring process, they do not conduct random tests for alcohol or drugs. Though I cannot speak for all of Canada's airlines, Air Canada, Canada's only scheduled service international airline, has instead instituted a peer-review process to assist pilots with substance abuse problems (personal communication, Mur-

\footnotetext{
${ }^{4}$ Drug and alcohol rules established for airlines are generally more stringent than those mandated by the Government of Canada.
} 
phy, March 22, 2014). Under this program, if a co-worker suspects a colleague is struggling with alcohol or drugs, the co-worker may refer the colleague to management. This individual subsequently undergoes a mandatory assessment and if the allegations of abuse are proven true, he is removed from aviation duties and placed in a rehabilitation program. Upon successful completion of this program, the individual is allowed to return to his aviation duties. To the dismay of the British Airline Pilots Association (BALPA), British Airways, has not introduced a peer-review process and, as of 2004, initiated random workplace drug testing policy for all UK-based staff (from baggage handlers to managers). Though I was not able to retrieve specific statistical data on how many people tested positive at British Airways, or how many pilots passed through the peer-review system at Air Canada, pilot unions (BALPA, ACPA, and ALPA - the Union that represents the pilots of 31 American and Canadian airlines) have consistently favoured a peer-review process over random drug testing in the workplace. ${ }^{\text {. }}$

The role of surveillance within the airline industry is not promising. New surveillance technologies to aid in aircraft communication and flight tracking are slow to be adopted and WestJet's FDMS preliminary surveillance project designed to monitor flight procedures was initiated by management rather than government regulators. Furthermore, FDMS was challenged under a national, rather than international labour code. When it comes to a common international alcohol and drug policy, national regulations are weak and inconsistent and corporate policies vary considerably. The fact that air space remains a national jurisdiction appears to play a role in this absence of congruency, but jurisdictional issues could still be resolved through a comprehensive international treaty. A question thus remains: what factors have prevented a comprehensive international treaty and what are the drivers of change within commercial aviation?

\footnotetext{
${ }^{5}$ I make this claim after aggregating data from the three interviews, the UK Railways and Transport Safety Act, BALPA's report, and James Coll and Michelle McCann's report.
} 


\section{CURRENT SURVEILLANCE PRACTICES OF COMMERCIAL FLIGHT OPERATIONS}

The 2001 terrorist attacks in New York City have drastically changed public perceptions of air travel. Not surprisingly, these concerns have been reflected in the policy-making processes of transport agencies internationally, whether these processes are public or private in origin. These new attitudes on the ways in which aircraft can be used as a weapon have resulted in sweeping reforms to the rules of air operations. All commercial aircraft are now equipped with a steel door separating passengers from the pilots and there is a legal procedure for pilots wishing to use the washroom. First, the pilot calls back to the flight attendant in the galley to inform her that he wishes to use the facilities. Next, the flight attendant discretely closes the curtain, then the pilot exits the locked door (which automatically locks behind him) and goes straight into the washroom. When he is finished, he radios the pilot still in the cockpit, who looks through the reinforced glass window to ensure it is safe to unlock the door. Once the pilot has safely returned to the cockpit, the curtain separating the passengers is discretely reopened. In the terminals, where pilots used to be able to bypass security checkpoints, they now have to go through security screening with the other passengers. Banned items such as nail clippers and pocket knives are confiscated from pilots as well as passengers.

These new forms of surveillance have, not surprisingly, generated discussion amongst pilots and their unions, academics, lawyers, and policy-makers. Though lawyers, academics, and policy-makers may commend the recent changes, pilot unions have consistently questioned their effectiveness and have raised concerns about undue discrimination and invasion of privacy (for example, pilots appear not to have accepted many legal arguments concerning the possibility that the nail clippers may be lost beyond security or that pilots may act in tandem with aspiring terrorists to bypass security).

However, while the procedures and discussions may be new, the way in which pilots expect airlines and regulators to implement these 
new regulations are not. Though no specific procedure, method, or trend is absolute, the implementation of any new regulations (whether it be a change in procedure or the implementation of a new surveillance technology) follows a cycle that airlines and regulators have traditionally argued has been very successful (personal communication, Anonymous Canadian Airline Management Member, March 31, 2014). Both airlines and the public institution responsible for air transportation regulation (in Canada, Transport Canada) invest heavily in accident investigations. Each time a procedure fails, no matter how small, a formal investigation takes place (Razaboni, 2013, p. 13). Despite the possibility of these investigations taking years to conclude, the accident report must provide a detailed analysis of not just what happened, but also the procedural and mechanical reasons that caused the accident. National and international regulators, as well as airlines then discuss adjustments to the rules of procedure or mechanics of an airplane to prevent a similar accident in the future.

This procedure was followed after the 2001 terrorist attacks. But instead of having a mechanical fire, or emergency procedural flaw, investigators concluded that the terrorist attacks occurred due to an absence of surveillance. The current procedures that were in place to prevent passengers with ill intentions from compromising the aircraft were deemed insufficient. The idea of hijacking an aircraft as part of a suicide mission was new and government officials felt that the learn from past mistakes system could no longer be solely relied upon for ensuring the safety of citizens.

\section{Flight data}

With the knowledge of the learn from past mistakes model in mind, it may now be understandable why, despite the technology being in place since 2000, MH370 did not have live streaming of its voice and data recorders. There simply has not been a recent accident where investigators were not able to locate the flight data recorders (black

\footnotetext{
${ }^{6}$ The sharing of accident information between jurisdictions appears to be very transparent.
} 
boxes). Thus, new surveillance technologies, such as cameras, data collection systems (including keyboard monitoring and control inputs), and live streaming of voice data have not been implemented. According to Air Canada pilot Blake Murphy, however, MH370 might change this. Furthermore, the less-than-positive response to $9 / 11$ now has pilots fearing that airlines and regulators will be overly reactive when it comes to implementing or adjusting procedures and practices. Thus, one can see how new surveillance technologies, which were previously implemented in response to an accident, but since 9/11 seem to be implemented without adequate evidence of improved safety (in the opinion of pilots), raise questions surrounding the appropriate surveillance and privacy of pilots.

\section{Is more surveillance an issue?}

One often understands surveillance as an action that compromises privacy of the person, or in this case, privacy of the pilot. I argue, however, that surveillance of pilots does more than compromise privacy. Though I disagree with David Lyon, who argues that people need to be concerned about "where the human self is located if fragments of personal data circulate within computer systems beyond any agent's personal control," there is still an abundance of negative outcomes that result from multiple surveillance systems that need to be addressed (Lyon, 19994, p. 18). But what are these negative outcomes and why are pilots generally not concerned with deviations in their perceived identity as a result of surveillance? First, pilots know that the nature of commercial air operations means an increased level of surveillance and thus increased fragments of personal data. For their own safety and the safety of others, the learn from past mistakes system has ensured that this surveillance is conducted under strict guidelines and the surveillance conducted is only what is necessary. Because surveillance is traditionally only conducted when it is necessary, I noticed a strong professional pilot culture in not questioning

\footnotetext{
${ }^{7}$ Since pilots always wear their headset, the black box records everything that is said, regardless of whether it is intended for the co-pilot, passengers, or the aircraft control tower. Wireless streaming of voice data would likely do the same.
} 
procedures and regulations. There is an immense trust not just in the regulations, but also in the expectation that pilots will follow them in all situations and at all costs. Refusing to do so would be unsafe and irresponsible. For example, one interview that I conducted with a Canadian pilot categorically ruled out the possibility of a fire on MH370 because a fire would mean the pilots would have broken procedure. Despite an airplane missing for a month, this pilot still had an immense trust that had there been a "textbook incident" (and the textbook encompasses nearly every possibility imagined), and procedure still would have been followed.

The second reason that ensures pilots need not be concerned about personal data fragments lies with the straightforward procedures of promotion at most commercial airlines. Because procedures must always be followed, there lies limited opportunity for pilots to contend for promotion on the basis of merit. Thus, promotions are handled purely on the basis of seniority. Unless a pilot is dismissed, pilots that were hired earlier enjoy greater choice and opportunity regarding the aircraft they fly and the routes they select. This limit to promotion restricts ambiguity on how their personal data is being handled and instills confidence that there will not be unfair discrimination from surveillance data (Bennett, 2011, p. 490).

Since the 2001 terrorist attacks, however, pilot trust in the system appears to be shifting. As noted earlier, the investigators determined that the 2001 terrorist attacks occurred due to an absence of surveillance. Thus, in accordance with the learn from past mistakes system, new surveillance mechanisms were expected to be implemented. Most passengers are probably familiar with some of these changes. There is now more comprehensive security at all commercial airports, limited liquids can be taken on board, and passenger name records must be sent to US Homeland Security for any flight travelling over the United States. As briefly mentioned in the previous section of this paper, pilots now have a procedure for using the washroom and must pass through the same security checkpoints as passengers. No passenger may visit the cockpit while in flight, and flights originating or terminating in the US must send the complete 
list of persons residing in the cockpit to Homeland Security twentyfour hours before departure (this means that a pilot not on duty who wishes to travel no longer has the right to sit in the jump seat unless planned the day before - a third seat in the cockpit that is commonly used for this purpose). Not surprisingly, many pilots appear to not be satisfied with these new rules. Many of these new post-9/11 procedures have been approached with caution from pilot unions such as ACPA. Concerning the possibility of cockpit cameras in response to MH370, Murphy indicated to me that ACPA would likely be systematically opposed ${ }^{\text {I }}$ The reason for this opposition is concerning because it threatens the integrity of the traditionally trusted learn from past mistakes system. Murphy argues that pilots increasingly do not see the correlation between recently implemented surveillance mechanisms and safety. That a pilot cannot take her nail clippers through an airport security checkpoint does not make sense to many pilots and induces (even if unintentionally) a lack of trust within the pilot's ability to safely care for her crew and passengers (personal communication, Anonymous Canadian Pilot Interview, March 15, 2014). Considering the immense responsibility entrusted to pilots, scepticism of the procedures and regulations is a clear reason for concern.

\section{Alcohol and drug testing}

It is for similar reasons that pilot unions, including ACPA, ALPA, and BALPA are opposed to random alcohol and drug testing. It is argued that these modes of personal restriction and invasion of personal integrity without just cause reflect an absence of trust in the pilot's ability to conduct his duties responsibly and care for his crew and passengers. Furthermore, unions argue that random alcohol and drug testing is not consistent with the learn from past mistakes system. All three pilot unions have argued that a system proven to most effectively manage alcohol and drug abuse amongst pilots is that which incorporates a peer-review process. Considering the risk of air travel,

\footnotetext{
${ }^{8}$ It is important to note that discussion surrounding cameras was only seriously considered after MH370 and Murphy emphasized to me that this is his personal prediction since ACPA's board has not actually formed an official opinion yet.
} 
some may be surprised that tort and statutory laws are not frequently cited and, at least in Canada, do not serve as the basis for the union grievances against alcohol and drug testing. In fact, random alcohol and drug testing has never been implemented in Canada or the UK by government regulators (Railways and Transport Safety Act, 2003). Concerning Canada, some lawyers have even suggested that corporate-based tests would have to test indiscriminately in order to not fall afoul of current human rights law (Coll \& McCann, 2013). In the context of the UK, BALPA remains unsatisfied with the current policy of random alcohol and drug testing because they feel that the peer-review process in place at Air Canada and major carriers in the United States is more effective in ensuring air safety without the intrusive surveillance of random testing.

We now know that it is rare for Western governments regulators, such as those in Canada and the UK, to conduct random alcohol and drug tests but despite all this discussion, I have yet to introduce any numbers to prove its effectiveness. ${ }^{1}$ Unfortunately, the only numbers I found in my research were a non-scholarly third-party source that suggests BALPA argued against random testing by citing statistics from the United States, where only ten pilots were caught abusing alcohol between 2000 and 2010 compared to five-hundred that entered a substance abuse program. Since the US does not have a formal drug testing policy in place, nor is there any widespread program of corporate testing, these numbers are sure to be inaccurate. In the spirit of adopting the learn from the past system, I decided I would include this question in my three interviews. While the anonymous Canadian pilot was unsure of the numbers, both Murphy and the anony-

\footnotetext{
${ }^{9}$ For simplicity and clarity, I use Canada and the UK as specific case studies of alcohol and drug testing. Though I cannot speak for every country in the world, I was not able to find any specific case anywhere in the world where public officials randomly test pilots for substance abuse. There are cases, however, of public officials (in this case, the London Metropolitan Police), randomly stopping crew buses "to board and welcome the crews to LHR and advise them of the regulations." According to the pilot bulletin, "the stop will only take three minutes and is an educational program" with the objective of providing information and educating crews of the UK alcohol regulations.
} 
mous management member refused to answer this question, citing confidentiality ${ }^{10}$ Though I do not intend to challenge the effectiveness of the peer-review process, I must gently point out that keeping the number of pilots undergoing rehabilitation confidential is not the best way to defend the integrity of the program.

\section{IV. "IT'S BREAKING APART": THE IMPACT OF SURVEILLANCE ON CURRENT PRACTICE}

Perhaps the least relevant, yet most humorous fact that I learned in my interviews is the last words of pilots before an accident - "Oh s***, it's breaking apart." Such a statement summarizes quite nicely the current surveillance situation of flight crew. The fact that there is increased secrecy, discontent, and distrust involving post-9/11 surveillance procedures is concerning as it threatens the willingness of pilots to follow procedures and regulations that prevent accidents and keep passengers safe. Such discontent necessitates further research into how surveillance has disrupted the learn from past mistakes system that was once so highly respected by pilots, management, and government regulators. Luckily, this surveillance upset that is brewing distrust and disruption is not as complicated as it may seem.

Let us start with the random alcohol and drug testing. As I mentioned in the first section, even though national borders do not contain commercial air travel, it is still national law that is supreme. In Canada, air travel falls under the jurisdiction of the federal government and thus, as far as privacy is concerned, commercial action must be consistent with the Personal Information and Protection of Electronic Documents Act of 2013 (PIPEDA). I do not see, however, how a random alcohol and drug testing policy would conflict with PIPEDA. There is a requirement that personal information (in this case, alcohol and drug samples and results) not be disclosed without personal consent (PIPEDA, 2013), however, a well designed program that is similar to the one in place at British Airways would likely account

\footnotetext{
${ }^{10}$ Despite a thorough search, I was also not able to gather these statistics from other sources.
} 
for this concern. Furthermore, if issues of consent from random testing were to be a problem, then arguably there would already be problems surrounding the mandatory testing of all new pilots, as well as the mandatory medical check-ups every six months (where any discrepancy is passed on to the airline and the pilot's health report is retained by the airline's doctor). As far as PIPEDA is concerned, the only clause that may conflict with a random testing policy is if pilots can prove that the collection of this personal information is not relevant to the safe operation of an airplane (the information is no longer used as intended since the intended application is irrelevant). In this respect, I do not feel that I could speculate as debate surrounding what is necessary would be outside the scope of this paper since it would require complex qualitative and quantitative evaluation of the current safety mechanisms (such as the peer-review process), and an evaluation of whether it would lead to a clear improvement in air safety.

Procedures involving data collection from flight management systems have been more contentious. Though I was not able to find any public statements regarding the US Department of Homeland Security's policy of registering every person in the cockpit twenty-four hours prior to departure, the two pilots I interviewed did not understand how the program increased safety. Though pilots appear (and claim) to comply, the inability or unwillingness for Homeland Security to actually consult with the experts on the ground (i.e. the pilots) means that pilots are less accepting of this new form of surveillance. It appears that in the eyes of aircrew, Homeland Security's approach on this issue does not reflect moderated steps from past mistakes but instead reflects a blanket surveillance policy that is unnecessary and ineffective. One Canadian pilot justified this approach as a "kneejerk reaction because they feel they have to do something immediate in response to the accident" (personal communication, Anonymous Canadian Airline Pilot, March 15, 2014). Surely this deviance from the learn from past mistakes model does not serve to increase pilot morale, nor is it consistent with the tradition of a respected mutual relationship between public regulatory bodies, commercial airlines, 
and their unions.

Unfortunately, however, there is more bad news. Since the disappearance of MH370, Murphy indicated to me that many airlines and regulatory bodies have begun to consider installing video cameras inside the cockpit. The "knee-jerk reactions" since the 2001 terrorist attacks have reduced trust between the pilot unions, management, and public agencies, resulting in pilots being concerned that there will be another unbalanced and unproven surveillance mechanism forcefully introduced into "their workplace" (personal communication, Murphy, March 22, 2014). Murphy indicated to me that though ACPA has yet to formally determine their position on this matter, it would likely be opposed to cameras, as they would be an unproven violation into a pilot's workplace.

One may argue, however, that the debate surrounding cameras in the cockpits is really not that new. As noted earlier, WestJet's FDMS also faced opposition when it was first introduced. Inconsistent with the learn from past mistakes model, FDMS was introduced not in response to an accident but in response to new technological capabilities. Though pilots were originally unclear of the benefits and drawbacks of this new form of surveillance, transparency on behalf of WestJet's management reassured them of the system's value in improving overall safety. Satisfied with the value of the project, pilots accepted the increased surveillance from the FDMS program. It will be interesting to follow how management and regulators will approach the question of cockpit cameras. Unless pilots are convinced, through transparent and genuine intentions, that this new surveillance mechanism will improve overall air safety, I suspect that they will continue to express discontent, and continue flying in reluctant compliance of the new reality.

\section{Conclusion}

In which ways have the recently installed security measures and procedures affected the surveillance of pilots, both inside and outside the workplace? Outside of the workplace, pilots undergo little scrutiny. 
The traditional environment of trust between the employer, pilot, and regulator appear to remain intact. In airports and on airplanes, however, surveillance of pilots has increased. Though the learn from past mistakes model has traditionally accounted for new modes of surveillance, there is now a divergence between regulators, management, and pilots when it comes to deciding what new modes of surveillance are necessary. Concerning pilots, this discontent has translated into a host of undesirable outcomes, including less trust in the procedures, lower morale, and new concerns that due process would not be followed in the event of a future accident. Considering the importance for pilots to have absolute trust in the procedures and regulations, this divergence should be a serious concern for passengers. The national nature of airline regulation, combined with limited government oversight in alcohol and drug testing, means that new relationships need to be negotiated on a case by case basis, sometimes between the pilots and the national regulator and sometimes between the pilots and management. As WestJet's FDMS installation suggests, however, one factor appears to be universal: only through transparent negotiation can the trust between pilots, management, and regulators be restored. Though I believe such reversal in the current trend is doubtful, one may hope that the investigation following MH370 uncovers areas of procedural improvement that is satisfactory to all three stakeholders, thereby improving pilots' trust in procedures and ultimately improving the safety of air travel. 


\section{REFERENCES}

Bennett, C.J. (2011). In defense of privacy. Surveillance and Society 8(4), 485-496.

British Airline Pilots Association. (2014). "Proposed EU rules put pilots over drink limit." Retrieved from http://www.balpa.org/ Newsand-campaigns/News/Archive/2011/PROPOSED-EU-FATIGUERULES-PUT-BRITISH-PILOTS-OVER.aspx

Bryant, S. (1995). Electronic surveillance in the workplace. Canadian fournal of Communication 20(4), 505-521.

Bygrave, L. (2013). Transatlantic tensions over data privacy. Transworld Working Paper no. 19 (ISSN 2281-5252).

Canadian Air Transport Security Authority. (2014). Non-passenger screening. Retrieved from http://www.catsa.gc.ca/non-passengerscreening

Coll, J. \& McCann, M. (2013). An issue of substance: Pilot drug and alcohol testing is a flight into uncharted territory. Canadian Skies, 82-84.

Defence, Science \& Technology Organization. (2014). Dave Warren inventor of the black box flight recorder. Australian Department of Defence. Retrieved from http://www.dsto.defence.gov.au/page/ $3383 /$

European Union. (2011). Commission implementing regulation (EU) no. 07/2011, Public Law L305/38, Official fournal of the European Union.

FlightRadar24. (2014). Full flight history for Malaysia Airlines Flight MH370. FlightRadar24. Retrieved from http://www.flightradar24. com/data/flights/mh370

Gilliom, John \& Monahan, Torin. (2013). SuperVision: An introduction to the surveillance society. Chicago: The University of Chicago Press. http://dx.doi.org/10.7208/chicago/9780226924458.001.0001

Government of Canada. (1985). Canadian Human Rights Act, Public Law H-6. Retrieved from http://www.Laws-Lois.Justice.gc.ca

Government of Canada. (2011). Personal Information Protection and Electronic Documents Act (PIPEDA), Public Law S.C. 2000, c. 5. 
Hanlon, J.P. (1990). Air travel: how safe is it? Tourism Management, 11(1), 83-84. http://dx.doi.org/10.1016/0261-5177(90)90016-3

Her Majesty's Government. (2003). Railways and Transport Safety Act 2003, Public Law C.20.

International Civil Aviation Organization. (2010). Convention on International Civil Aviation - Doc 7300. International Civil Aviation Organization. Retrieved from http://www.icao.int/publications/ Pages/doc7300.aspx

International Society of Air Investigators. (2014). Technical papers. International Society of Air Investigators. Retrieved from http:// www.isasi.org/

Johannessen, R. (1979). The VHF radio lighthouse. The fournal of Navigation, 32(3), 320-324. http://dx.doi.org/10.1017/s0373463300026199 Lyon, D. (1994). The electronic eye: The rise of the surveillance society. Minneapolis: University of Minnesota Press.

Lyon, D. (2007). Surveillance studies: An overview. Cambridge, UK: Polity Press.

Lyon, D. (2008). Biometrics, identification and surveillance. Bioethics, 22(2), 489-499. http://dx.doi.org/10.1111/j.1467-8519.2008.00697.x

Lyon, D. \& Bennett, C. (2008). Playing the identity card: Understanding the significance of identity card systems. In Lyon, David and Colin Bennett (Eds.), Playing the identity card: Surveillance, security and identification in global perspective. New York: Routledge

Martinelli D.R., Napolitano, M.R., Windon D.A., \& Casanova J.L. (1998). Virtual flight data recorder for commercial aircraft. Fournal of Aerospace Engineering, 11(1), 17-22 http://dx.doi.org/10.1061/(asce)0893-1321(1998)11:1(17)

Perry, Nick \& Eileen Ng. (2014, April 5). Chinese ship detects "pulse signal" near MH370 Search Zone. The National Post. Retrieved from http://news.nationalpost.com/

Rakas J., Hansen, M., Jirajaruporn, W., \& Bolic, T. (2003). User request evaluation tool and controller-pilot data link communications: Integration benefits assessment. Transportation Research Record 1850(1), 20-29 http://dx.doi.org/10.3141/1850-03

Razaboni, P.M. (2013). Instant flight data analysis: International society of sir safety investigators. Retrieved from http://www.isasi.org/ 


\section{Library/technical-papers.aspx}

Regan, P.M. (2013). Regulating surveillance technologies. In Kristie Ball, Kevin Haggerty, and David Lyon (Eds.), Routledge Handbook of Surveillance Studies. New York: Routledge. http:/dx.doi.org/10.4324/9780203814949

Smith, A.E. \& Evers, C. (2003). Method and apparatus for improving utility of automatic dependent surveillance. Rannuch Corporation. Vol. US 6633259 B1. United States.

Transport Canada. (2014). Backgrounder - Canadian Air Transport Security Authority (CATSA). Retrieved from http://www.tc.gc.ca/ eng/aviationsecurity/page-168.htm

Transport Canada. (2004). Canadian Aviation Executives' Safety Network Annual Meeting Report. 765689th Congress. 